\title{
Technological Innovation Green Remediation
}

\author{
Liang $\mathrm{Li}^{1}$, Li Wei ${ }^{2}$, Zhengyong $\mathrm{Lv}^{2}$ \\ ${ }^{1}$ Land Reserve Center of Suzhou, Suzhou Jiangsu, 215004, China \\ ${ }^{2}$ Beijing High Energy Era Technology Co., Ltd. Beijing, 100095, China
}

Keywords: Technological innovation, Green remediation.

\begin{abstract}
Soil remediation has been a world puzzle for a long time. Suzhou land reserve center has selected Beijing GeoEnviron Engineering \& Technology. Inc. (hereinafter referred to as GeoEnviron) through bid invitation during the process of organizing Suzhou Solvent Factory pollution remediation. The company has organized and developed major core equipment for soil remediation through introducing overseas technology. This set of governance system and remediation equipment have provided effective method to Suzhou soil remediation and also explored valuable experience for soil remediation in different areas.
\end{abstract}

\section{Introduction}

Remediation project is located in Gusu District, Suzhou City, which is a golden area of ancient town of Suzhou City. The project was the site of Suzhou Solvent Factory of Suzhou Chemical Pesticides Group. The land was dismounted in 2007 and transferred to municipal land reserve enter. As the large contaminated area and severe pollution, and difficulty of pollution abatement, the land has been in reserve state since 2007 to 2012.

Reserve land pollution regulation work in Suzhou urban district started in 2011. Municipal government attached great importance to the work and established urban reserve land pollution regulation leading group and working coordination work led by the major and branched deputy major. Working coordination group has adhered to the working principle and style of making concerted cooperation, challenge facing, innovation and seeking improvement in stability, successfully completed three small land pollution abatement in former Suzhou Special Chemicals Company, former Suzhou Anli Chemical Plant, and former Suzhou Machinery Instrument Electroplate Factory. Then since 2012, it officially put pollution abatement in Suzhou Solvent Factory on the agenda. At present, the whole site remediation governance work is forging ahead stably as scheduled. Suzhou Chemical phase one project has entered into safe stable operation stage. Now introduce pollution treatment work as follows:

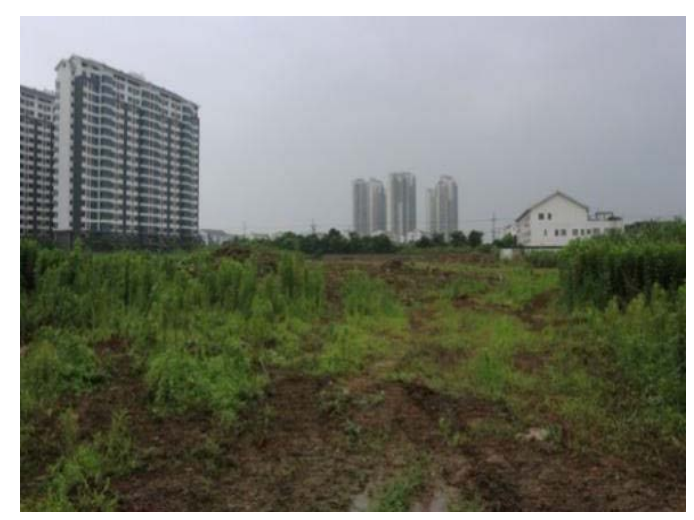

Figure 1. Original appearance before site remediation and treatment 


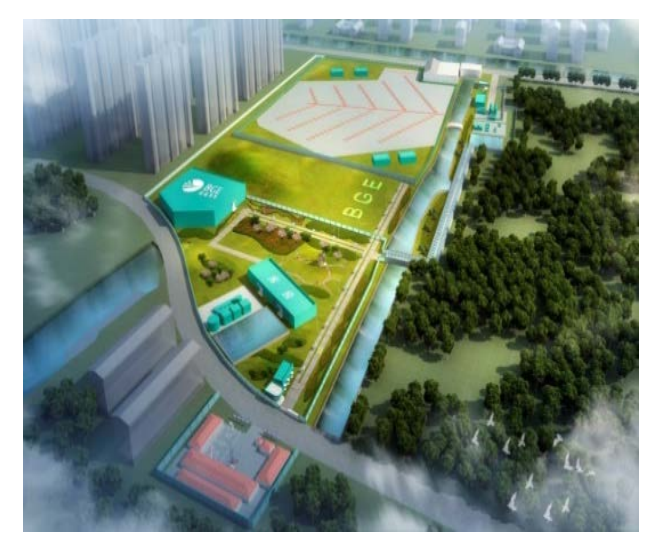

Figure 2. Effect picture of remediation and treatment site

\section{Screen remediation technology and optimize remediation route}

Suzhou chemical phase one project covers an area of about 46000 square meters. Since April 2012, Suzhou Institute of Environmental Science entrusted by land reserve center has conducted preliminary investigation, detailed survey and risk evaluation on the land pollution condition. Survey results show main pollutants in the land include benzene, chlorobenzene, and petroleum hydrocarbon, the largest out of limits for 81.8 times, with a pollution depth of-18m, pollution area of about 18000 square meters and polluted soil volume of about 280000 cubic meters.

To screen remediation technology and optimize remediation process route, land reserve center has conducted pilot test bid invitation since Sep 2012 and selected three among 17 for site pilot test. CAS Nanjing Soil Institute conducted comparison and formulation of remediation technology process based on pilot test results, and finally selected in situ thermal desorption technology which is fast, complete pollutant removal and small secondary pollution as main treatment technology. The whole land purpose has not been confirmed yet. Considering the settlement buildings in the north have been completed, according to domestic authoritative experts' repeated research and demonstration, the remediation goal will be applied with the strictest residential land standard as remediation treatment target, i.e. benzene concentration in restored soil lower than the target value $0.15 \mathrm{mg} / \mathrm{kg}$, chlorobenzene concentration lower than $2.0 \mathrm{mg} / \mathrm{kg}$, benzene concentration in underground water lower than 0.1mg/L. In April 2016, the land reserve center has conducted bidding on the phase one project. 14 companies participated in bidding and finally GeoEnviron won the bidding of project remediation treatment work at the bidding price o RMB 0.258 billion by using in situ electrical heating thermal desorption technology.

\section{Organize scientific research tackling team to develop remediation equipment}

In June 2016, remediation implementation unit GeoEnviron has established a project implementation and management team containing 50 staffs with rich experience. Project team leader is the chief engineer of remediation company, and the team is directly led by the general manger of the remediation company. Since June 2016 up to now, the project implementation team has successfully completed work in three stages: project early-stage preparation stage, project construction stage, project operation stage. Main working contents include: site pollutant status double check, site pollution model building, core technology and equipment introduction, remediation treatment construction organization design, successful land of localized equipment (equipment domesticization of heating system, electricity distribution system and off-gas treatment system), construction, installation and debugging of heating system, installation and debugging of electric power distribution system, installation and debugging of off-gas treatment system.

\section{Early-stage preparation stage}

1) Pollution state double check and establish precise pollution site model. It has been two years 
from site investigation to remediation governance implementation. To precisely obtain the pollution transfer status and provide powerful technical support for precise design of heating system, GeoEnviron has conducted further pollution status double check on the site by using advanced survey devices, and collected 432 soil samples and 82 underground water samples, and sent to the third party authority lab for survey analysis. Then establish pollution model based on site investigation results to provide powerful data support for the distribution and setting of heating well, temperature monitoring well and monitoring well.

2) Use foreign big data and technical advantages for comprehensive simulation of governance process and complete remediation scheme design. To safely and stably promote project governance to be smoothly implemented, GeoEnviron introduced world first-class in situ electrical heating thermal desorption technology1 to China, and achieved equipment domestication. In the project, US TRS as technical support unit, based on pollution survey and re-check data, combined domestic environmental and power policies, TRS experts led GeoEnviron technical team to complete project overall design. During the whole design process, they fully developed the big data advance accumulated in foreign side for comprehensive simulation of governance process. In the process, five experts of the foreign side participated in all-around way.

3) Successfully developed high quality core equipment suitable for Chinese national condition and achieve world leading level. GeoEnviron technical team has pursued excellence based on introducing foreign core equipment and independently developed an electric power distribution and control system with higher automatic control level, broader pressure control scope in the beginning of 2017, and successfully applied to former pilot test areas which was the hardest area in project region (high pollution concentration and depth and huge manual disturbance of pollution). Governance effect has achieved global first-grade level. The electricity control and distribution system is suitable for domestic utilization policy and applicable to any area in China with no barriers.

4) Domestic top level industry experts provide comprehensive guidance to guarantee the optimization of remediation governance scheme design. To guarantee the scientificity and exploitativeness, GeoEnviron has organized domestic top industry experts since project initiation who are from CRAES, Nanjing Institute of Environmental Sciences(NIES), Ministry of Environmental Protection, and Institute of Soil Science, Chinese Academy of Sciences. They have conducted comprehensive demonstration on each procedure of remediation governance from remediation technology process to secondary pollution control, and proposed optimization suggestion to escort the project for smooth implementation.

\section{Project construction stage}

1) Spent three months successfully completing the construction of more than 600 electrode wells with an electrified rate of $100 \%$. Project management team made perfection more perfect and compensated the insufficient experience in electrode well construction, and spent three months completing the construction of more than 600 electrode wells, solved five kinds of electrode well special padding selection problem and underground special cable vulnerability problem. For the first time propose to apply modified fluoroplastics to cable insulation jacket to successfully solve the problem that cable is vulnerable in underground high temperature and high pressure environment. The electrode well electrified rate achieved $100 \%$ which exceeded the average level in foreign countries.

2) Independently developed triple secure coating to avoid pollutant dissipation. To avoid pollutant steam dissipation and cause foreign taste at governance site, GeoEnviron has combined soft seepage prevention2 with rigid seepage-proofing, and built soft seepage-proofing layer, equipotential and rigid impervious barrier from bottom up on the surface of heating governance area mainly for strengthening steam stripping effect and guarantee operator security and reduce heat loss. The step voltage of equipotential reduces to below $10 \mathrm{~V}$, lower than national standard limit value $36 \mathrm{~V}$ to effectively guarantee operator's security.

3) Complete surface pipeline installation in high quality and pollution steam transport with no leakage. To guarantee all pumped pollution steam to be transported to off-gas treatment system with 
no leakage, GeoEnviron uses natural gas pipeline as the transport pipeline and conducted pressure test after installation completed to verify the impermeability of pipeline installation so as to guarantee no leaking point in transport pipeline and no leakage of pollution steam.

4) Rapidly completed equipment installation debugging, and explored a set of quality control system. GeoEnviron spent three months completing installation and debugging of power control equipment, off-gas and wastewater treatment equipment. During equipment installation process, GeoEnvrion has explored a set of quality control system such as using red, yellow and blue to mark different phases to greatly improve the efficiency of power cable installation and effectively avoid misconnection of phases and short circuit due to too many power cables.

\section{Governance process stage}

During the governance process, there was no off smell no exceeding noise and small influence on surround environment. Since energization and heating in August 2017, more than 8000 square meters have been heated to improve the overall area to $60^{\circ} \mathrm{C}$, and even above $100^{\circ} \mathrm{C}$ in some areas with no off smell at site and noise under $50 \mathrm{db}$, up to national relevant standard and acceptable by surrounding residents. GeoEnviron has established systematic management in in situ thermal desorption operation and cultivated a professional team proficient in in situ thermal desorption remediation technology.

Exhaust pollutant zero emission for successive 70 days and wastewater reaches the standard municipal pipe for deep processing. For the obvious off smell in domestic pollution site, in the end of 2016, GeoEnvrion has firstly proposed sequential control off-gas adsorption system to deal with off-gas impact load and to effectively solve off-gas pollutant concentration large fluctuation and difficult handling and obvious off smell at site. Suzhou Chemical phase one project used advanced control measure to achieve exhaust pollutant zero emission for successive 70 days and wastewater reaches the standard municipal pipe for deep processing in waste water factories. During treatment process, all pollutants were not discharged into environment directly.

\section{Establish green concept and lead industry development}

1) Establish scientific management mechanism. Pollutant site treatment is complicated, involving a lot of departments. Under the influence of social situation and people's environmental ecological awareness, GeoEnviron has met a lot of new conditions and problems such as environment influence evaluation government review and approval, heavy load temporary electricity application for installation, near water access and waste water pipeline reception, secondary pollution control, social stability control, etc. Suzhou has fully developed the role of governance working group and solved cross-functional coordination problem, established expert think tank constituted by professional staffs from universities and colleges, scientific research institutions and experts working in contaminated soil investigation and governance so as to guarantee governance work to proceed scientifically, stably and orderly and establish a management mechanism with Suzhou characteristics.

2) Realize remediation equipment domesticization. Advanced technology requires for core equipment as support and core equipment manufacturing is limiting the development of pollution governance technology. During the development process of pollution site governance technology, introducing partial advanced technology cannot realize remediation equipment domesticization so that its application is limited. GeoEnviron introduced advanced in situ thermal desorption remediation technology to successfully realize core equipment domesticization. It symbolizes that China has fully controlled the advanced technology as the precedent of introducing and digesting foreign advanced technology, and opened up new path for pollution site governance technology development.

3) Lead industry technology development. GeoEnviron established joint company with foreign supporting unit to fully develop foreign technical strength, obtain the technical authorization of in situ thermal desorption patent technology, and fully control in situ thermal desorption remediation technology, introduce international management concept, and establish a internationally compatible project management team to produce a demonstrative effect on the rapid development of pollution 
site governance industry.

4) Create a pollution treatment pioneer. With the tightening environmental protection policy and the increase of ecological environmental protection from the society, pollution site governance inevitably developed from heavy excavation and large-disturbance motion to ex-situ remediation to non-exaction and micro-variations in-situ remediation. Particularly the out-site events have rapidly accelerated the development process. As soil pollution has concealing characteristic so that some in situ thermal desorption technology cannot reach ideal remediation effect. The implementation of the project has created a new pattern of in situ remediation and created the pioneer of permanently removing target pollutants in soil and eliminating soil pollution.

5) Create green remediation concept. With the normalization of environmental protection, a lot of pollution site governance project has become new pollution source with obvious influence on surrounding environment during governance process. GeoEnviron applies green clean electricity as energy of in situ thermal desorption in the project with small secondary pollution risk and small influence on surround environment, small damage to soil environment and high acceptation among residents. It has created a green sustainable remediation concept. There is no off smell at governance site and soil after governance is not different from normal soil, thus will not influence the subsequent planning purpose of the land.

6) Establish governance sample project. Pollution site governance is a sensitive problems concerned by the public. Any negligence may cause factors leading to social instability. Thus, GeoEnviron made timely analysis, controlled risks and made various pre-arranged planning so as to guarantee the stable and secure work in pollution site governance. During the process of Suzhou chemical phase one governance, the company has selected in situ thermal desorption technology which is environmentally friendly, and applied internationally advanced sequential control off-gas absorption system to avoid secondary pollution from the source; meanwhile, it has analyzed and studied technology, secondary pollution control and prevention, secure and stable risk control so as to guarantee the governance to be carried out smoothly. Next, the company will focus on project implementation and establish pollution site governance sample project so as to build it into the training base of domestic pollution site governance.

\section{References}

[1] Jerry Wolf, Tracy Barton,Thiago Gomes, Davi Damasi. Electrical Resistance Heating: Rapid Treatment for Soil and Groundwater Remediation.

[2] Liu Yong, Feng Qilin, Liu Lei, Zhang Qian. Studies on ecological barrier system application technology in solid waste treatment process, Environmental Sanitary Engineering, 2010, 18(06):21-22+25.

[3] Gu Qingbao, Hou Deyi, Wu Bin, Jiang Xiaoyu, Li Fasheng. Revelation of pollution site green sustainable remediation concept, project implementation on China, Chinese Journal of Environmental Engineering, 2015, 9(08):4061-4068. 